\title{
The experimental identification method of the dynamic efficiency for frequency regulation algorithms of AEDs
}

\author{
Vladimir L. Kodkin, Aleksandr S. Anikin \\ Departement of Theoretical fundamentals of electrical engineering, South Ural State University, Chelyabinsk, Russia
}

\begin{tabular}{l}
\hline \hline Article Info \\
\hline Article history: \\
Received Jul 30, 2020 \\
Revised Jan 12, 2021 \\
Accepted Jan 29, 2021 \\
\hline
\end{tabular}

\section{Keywords:}

Dynamic efficiency Experimental identification Scalar control Variable frequency drive Vector control

\begin{abstract}
The article proposes and substantiates a method for studying the dynamics of an asynchronous electric drives with frequency control from the input side of the signal for setting the speed of rotation of the electric motor. In this method, a constant speed reference signal is added to a harmonic variable frequency signal. The set of amplitude changes and phase shifts of velocity oscillations are the initial data for identifying the dynamics of the studied control method. The logic of this method is determined by the previously obtained nonlinear transfer function of the link that forms the mechanical moment in the asynchronous electric drive with frequency control. Experiments have shown the dynamic benefits of the drive with positive stator current feedback.
\end{abstract}

This is an open access article under the $\underline{C C B Y-S A}$ license.

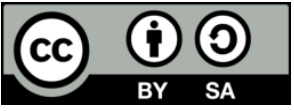

\section{Corresponding Author:}

Aleksandr S. Anikin

Departement of Theoretical fundamentals of electrical engineering

South Ural State University

76, Lenin prospekt, Chelyabinsk, Russia. 454080

Email: anikinas@susu.ru

\section{INTRODUCTION}

Asynchronous electric drives with frequency control (AED) are widely used in various areas of industry and energy. Until recently, the units with which these drives work had similar operating modes. These modes can be characterized as static or quasi-static [1]-[4]. The required rotational speeds of electric motors in these drives remain unchanged for a sufficiently long time or change very slowly. In this regard, the main characteristics of the drives remained static characteristics: slip, efficiency, power factor, Requirements for dynamic modes (time of the transient process, the lag of the change in the rotation speed from the change in the reference signals) remained secondary. This situation has now changed. Very often it is required to justify and select such a control method that will provide fast and accurate speed "reproduction" of AEDs complex and often quite dynamic reference signals. This dynamism of reproduction determines the efficiency of the entire mechanism or complex with which the electric drive works.

There are several "new" features of complexes with asynchronous electric drives:

1) Units and mechanisms, which are equipped with AED, become more complicated and optimized by technology, in connection with which static modes of operation require clarification and become dynamic or "quasi-dynamic", i.e. the speed of rotation of the electric motor in them "adjusts" to the operating conditions [5], [6]. Such mechanisms include, for example, pump drives in power systems, which seek to optimize operating modes for resource consumption.

2) Efficiency and good overload capacity of asynchronous electric motors require their implementation in areas where they were not previously used. Despite the fact that the advantages of permanent magnet synchronous motors and DC motors as control objects over asynchronous motors remain, in some cases 
the use of the latter is highly desirable. An example of such an application can be traction drives for unmanned aerial vehicles. The required speed and torque control ranges, usually not exceeding 1:10, can be implemented on asynchronous electric drives, and the advantages of the latter in weight and load capacity will become advantages. In this connection, it is necessary to determine their dynamics, i.e. to determine the "limits" of the dynamic characteristics of the AED that can be implemented [7]-[9].

3) Classes of drives, in which it is absolutely necessary to solve dynamic problems precisely on the basis of AED, have been identified. Such areas include, for example, wind power plants operating on a common power supply system [10]. In such installations, the conversion of mechanical wind energy into electrical energy is carried out using a double-feed electric machine. It is an asynchronous electric motor with a wound rotor, into the circuit of which a frequency converter is connected. This allows you to "adjust" to non-stationary air flows and generate "green" electrical energy of a fixed amplitude and frequency.

The choice of the most dynamic way to control an asynchronous electric drive is complicated by the following circumstances:

1) When used in control systems, vector nonlinear equations that describe AEDs [11]-[13] should be greatly simplified and linearized. This will inevitably lead to significant identification errors and possible control errors. Therefore, the use of known methods for identifying the dynamic characteristics of closed automatic systems by their mathematical description [11]-[13] is unlikely to be effective. AEDs with frequency control is an essentially nonlinear system, and the traditional control methods (vector and scalar) for them are formed under a number of significant assumptions [2], [3], [6]. As a result, theoretical conclusions often do not coincide with practical results.

2) The experimental results obtained under the same conditions, for example, at stator voltage frequencies (and, accordingly, rotation speeds) close to the nominal ones, are not confirmed at speeds two to three times lower. This is a consequence of the same drive non-linearities.

3) Very often, the control algorithm, which is optimal in terms of consumed resources and dynamics for the nominal mode, becomes emergency for other speeds. The solution of all these and other problems is very important for modern industry and energy, in which AEDs are most widely used, therefore, the assessment of the dynamic capabilities of one or another AED control algorithm from the point of view of increasing the efficiency of its operation in this mode is an extremely urgent taskThe way to solve this problem can be not only theoretical, but also experimental.

\section{PROBLEM DEFINITION}

Traditionally, of all the existing AED control methods, vector control with feedback on the speed of rotation of the motor shaft is distinguished [14]-[17]. According to many sources [17], [18], this method of control is considered to be the most "dynamic". However, a series of experiments [19], [20] showed that vector control does not have an unconditional "dynamic" advantage. Moreover, forced scalar control with dynamic positive stator current feedback (DPF) without direct measurement of speed has almost the same transients in step speed reference Figure 1 as transients in vector control Figure 2.

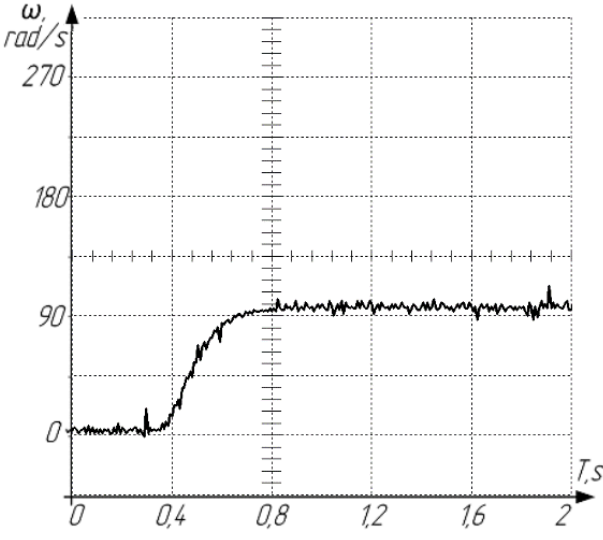

(a)

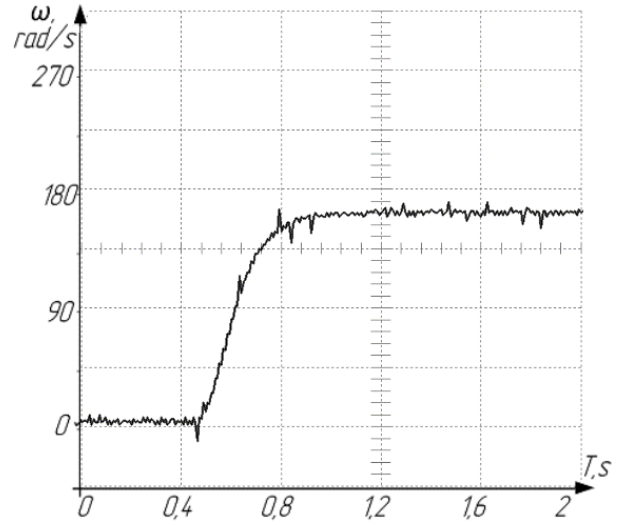

(b)

Figure 1. The processes of acceleration of the drive with DPF up to speeds of $90 \mathrm{rad} / \mathrm{s}$ (a) and $170 \mathrm{rad} / \mathrm{s}$ (b) 


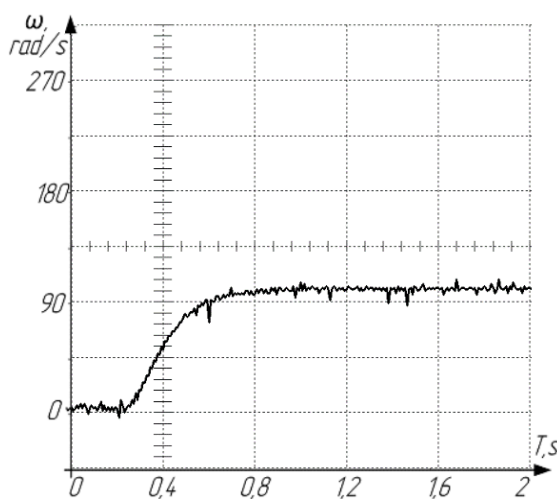

(a)

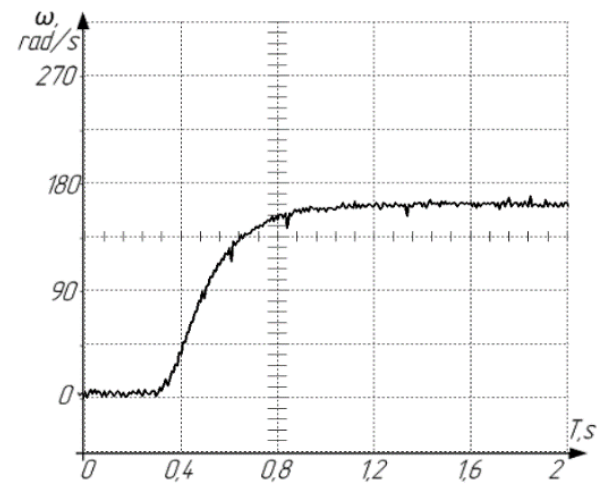

(b)

Figure 2. Processes of acceleration of a drive with vector control up to speeds of $90 \mathrm{rad} / \mathrm{s}$ (a) and $170 \mathrm{rad} / \mathrm{s}(\mathrm{b})$

The analysis of a number of parameters of the AED operation, according to specially developed methods [19], [20], including the spectra of currents of the rotors of asynchronous electric motors [21], [22], showed that the errors in vector control are very significant. These errors are caused by assumptions inevitable in the synthesis of vector control equations. In many studies [2], [8], [19] it is noted that the "discrepancies" of the parameters of the motor model used in the vector control algorithm with the parameters of a real motor are very significant and can give significant errors in control. However, it is no less important that the rotor and stator currents are non-sinusoidal and contain harmonics that differ from the fundamental harmonic that forms the torque in the AED. And vector control "in principle" neglects them, controlling only the fundamental harmonics of current and voltage. One way or another, according to experiments with acceleration to various speeds, the "advantage" of vector control is insignificant. This may indicate both a not too "subtle" method of experimental evaluation of the dynamic properties of a drive, and about the same dynamic efficiency of control methods, which contradicts the generally accepted concepts of "dynamic" vector control. To obtain accurate conclusions, a more "subtle" experimental technique is required.

\section{SOLUTION}

\subsection{Theoretical substantiation of the method}

To assess the AED by dynamic characteristics, a nonlinear transfer function of the link that forms the electromagnetic torque in an induction motor was proposed [19], [23]. It looks like this

$$
W(p)=\frac{2 M_{k}\left(T_{2}^{\prime} p+1\right) S_{k}}{\omega_{1}\left[\left(1+T_{2}^{\prime} p\right)^{2} S_{k}^{2}+\beta^{2}\right]}
$$

where, $T_{2}^{\prime}=\frac{L_{k}}{R_{2}}-$ the transient time constant of the rotor, $\beta=\frac{\omega_{2}}{\omega_{1}}-$ the relative slip, $M_{k}-$ the critical moment, $s_{k}-$ the critical slip at the nominal frequency $\omega_{1}$

The block diagram of the AED with such a link is shown in Figure 3. As can be seen from formula (1), the function changes when the frequency of the stator voltage $\omega_{1}$ and the absolute slip $\beta$ change. In addition, it should be borne in mind that when $\omega_{1}$ changes, the critical moment $M_{k}$ also changes. When accelerating from one frequency $\omega_{1}$ (in this case $10 \mathrm{~Hz}$ ), to another frequency $\omega_{1}(50 \mathrm{~Hz})$, the frequency characteristics change from W1 to W2 and W3 Figure 4.

Sophisticated methods of analysis of nonlinear systems and methods of their linearization [24], [25] make it possible to assess the stability of such systems in engineering analysis, but it is rather difficult to theoretically substantiate the advantages of one or another AED control algorithm with variations in the reference signals. In this regard, an experimental technique is proposed that allows you to evaluate the effectiveness of a particular control method. It is with these signals that variables are best interpreted. nonstationary task signals that are processed by automatic control systems in optimized complexes in robotics and power engineering. 


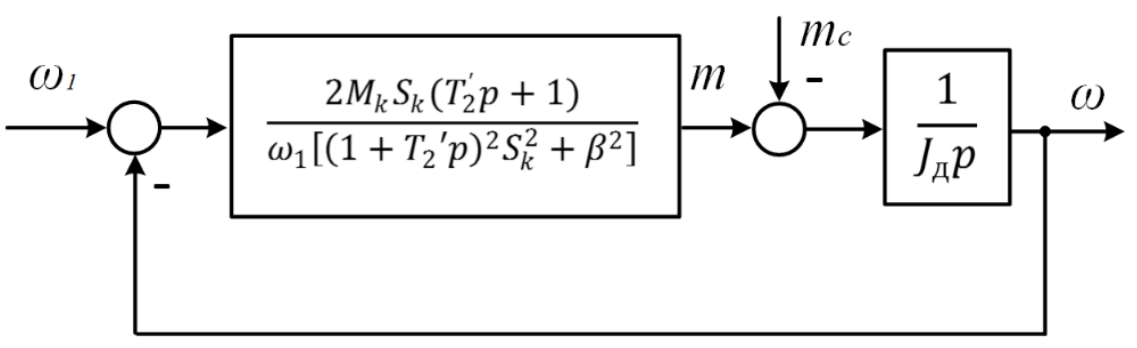

Figure 3. The working section of the mechanical characteristics of the induction motor

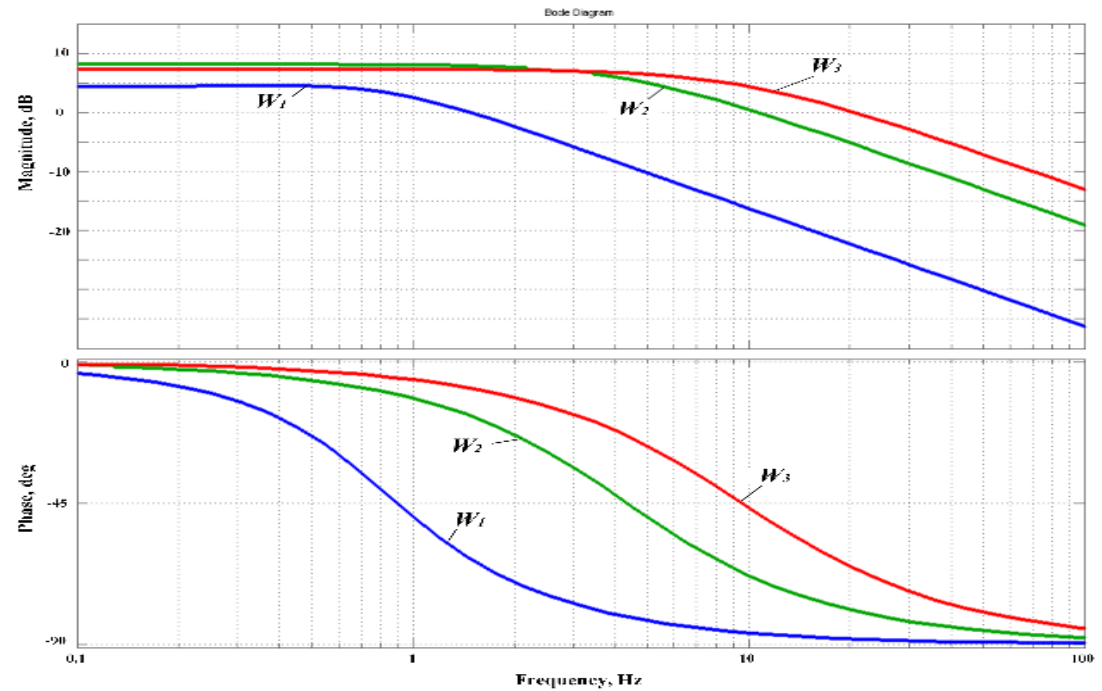

Figure 4. Frequency responses of an electric motor at a stator voltage frequency of $10 \mathrm{~Hz}(\mathrm{~W} 1), 30 \mathrm{~Hz}(\mathrm{~W} 2)$, $50 \mathrm{~Hz}(\mathrm{~W} 3)$

\subsection{Results of experiments}

The experiments were carried out on the stand shown in Figure 5. The phase rotor of the M1 motor allows you to control not only the stator currents, but also the rotor currents. A special generator SG1 allows you to generate a task signal of any complexity. Since the AED is an essentially nonlinear system, it is not enough to obtain an estimate of the dynamics only by the response to a step task. Therefore, the drive speed reference signal is generated as the sum of a constant value signal and a sinusoidal signal generated in the SG1 signal generator. Since the transfer function changes with a change in the frequency of the stator voltage, the experimental identification must be carried out at several of the most characteristic frequencies of the stator voltage and rotation speeds of the electric motor.

For this, during the experiments, the constant components of the task signals, corresponding to 10 , 20, 30 and $50 \mathrm{~Hz}(30,60,90$ and $150 \mathrm{rad} / \mathrm{s})$, were selected. These speeds are set by potentiometer R1. The sum signal is fed to the input of the frequency converter AI1. The amplitude of the periodic component of the reference signal from the SG1 generator should be no more than $10 \%$ of the level of the DC component in order to slightly change the transfer function of the link of the electromagnetic torque driver $\mathrm{W}$. The frequency of the periodic component of the reference signal is in the range from 0 (step reference) to $5 \mathrm{~Hz}$, of which $0,0.41,1$ and $5 \mathrm{~Hz}$ were chosen. During the experiments, the speed setting signal and the real value of the motor shaft rotation speed were recorded. The signals are "collected" in the PG digital oscilloscope and transferred to the laptop. The dynamic property identifiers will be the recorded amplitude differences and phase shift between these signals. A more dynamic automatic system "works out" the reference signal with less amplitude attenuation and less phase shift. [20], [23]. 


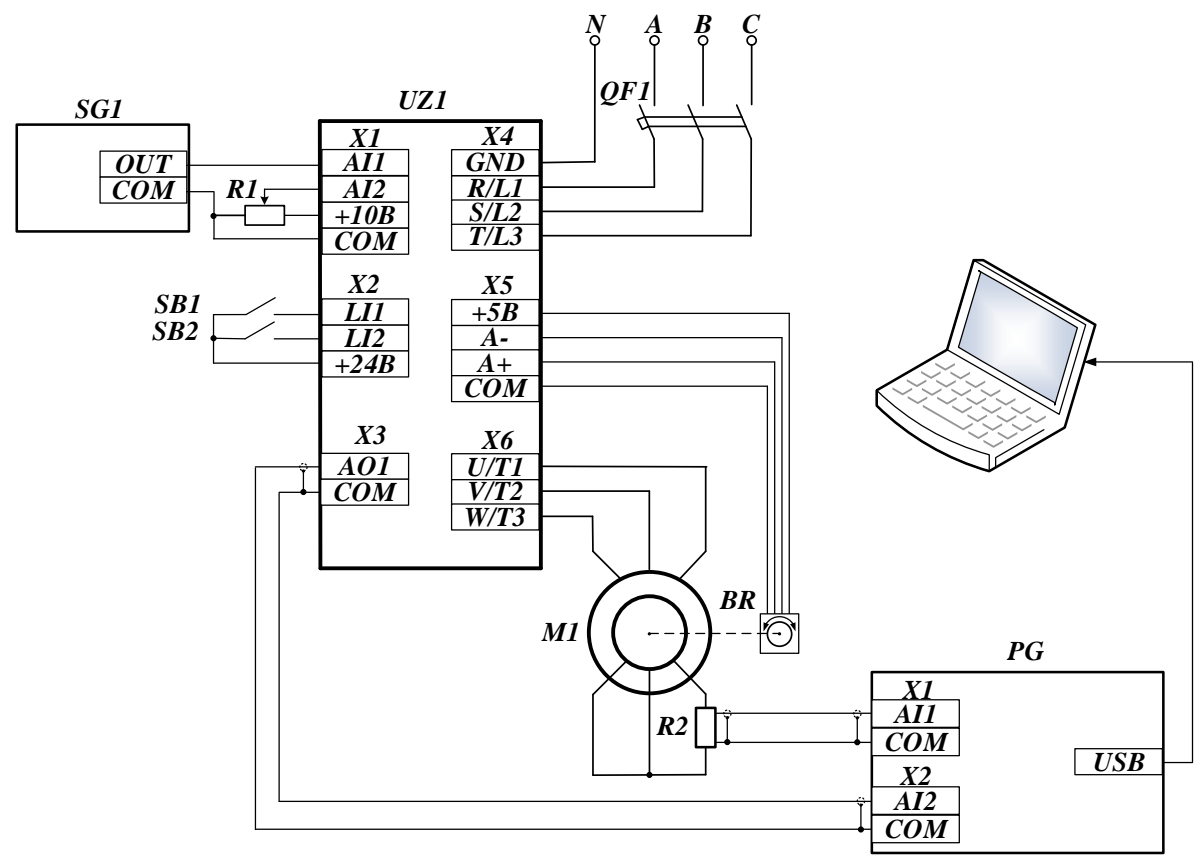

Figure 5. Schematic diagram of the drive with the slip-ring induction motor for the study of the dynamic characteristics of the drive (SG1- signal generator; UZ1 - frequency converter; BR - encoder; PG oscilloscope; M1 - slip-ring induction motor)

The proposed method is close to the identification method described in [11], [13]. Unlike identification objects considered in [11], an asynchronous electric drive cannot be described by a linear fractional-rational function [8], in this case, the transfer function of the drive should be "redefined" by the frequency of the stator voltage, after which the input and output signals of the electric drive. With the same reference signal Figure 6, three sensorless ones - scalar and vector control Figure 6(a) and four control methods were analyzed: vector with speed feedback Figure 6(b), scalar control with DPF Figure 6(c). The speed diagrams in a drive with open loop control algorithms for scalar and vector control have minor differences, therefore they are presented in one graph Figure 5(a). The exact results of measurements of differences in amplitudes and phase shifts of all experiments are presented in Table 1. In almost all cases, control with DPF has some advantage, which was noted earlier in the analysis of the response to a stepwise action. For the amplitudes of the fundamental harmonics of the speed change (we are large $6.4 \mathrm{rad} / \mathrm{s}$ versus 5.0 and $4.99 \mathrm{rad} / \mathrm{s}$ ) and for the phase shifts between the task signal and the actual speed (the least 72 versus 84 el. Deg) in all experiments, the best results were obtained in a circuit with a DPF on the stator current.

One of the reasons for this should be recognized that this control method "works" with all harmonics of the motor currents, in contrast to sensorless vector control and vector control with speed feedback. As shown in [20], the DPF linearizes the nonlinear transfer function of the AED. However, the reasons for the advantages of scalar control with DPF are not the subject of this work. Subsequently, the proposed method for identifying the AED dynamics was applied to a more complex input signal Figure 7. This is an example of a triangular reference. This complex signal, with a peak value of $2 \mathrm{~V}$, was added to the constant reference signal to rotate the motor at $90 \mathrm{rad} / \mathrm{s}$, i.e. corresponding to a stator voltage frequency of $30 \mathrm{~Hz}$. The duration of the "triangle" cycle is $1 \mathrm{~s}$. The output signal measured the maximum value in Volts and the phase shift in seconds. Figure 7 shows the reference signals and signals of the AED rotation speed for three control methods. Enlarged diagrams for AED with scalar and vector control Figure 8(a) and with DPF Figure 8(b) and the amplitude of the speed diagram $(0.89 \mathrm{~V}$ versus $0.68 \mathrm{~V})$ and the phase shift $(0.23 \mathrm{~s}$ versus $0.37 \mathrm{~s})$ for the AED with DPF are noticeably better. 


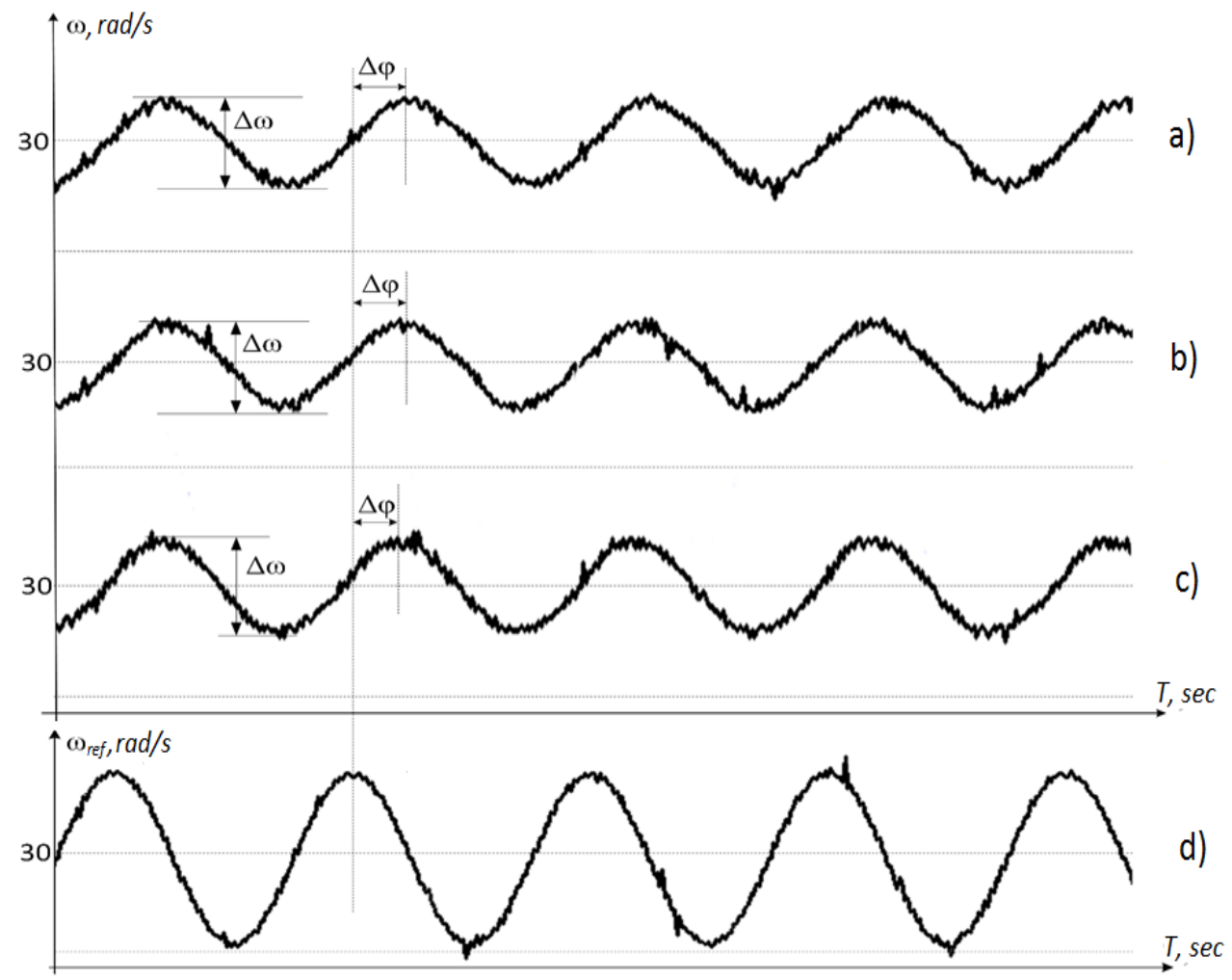

Figure 6. Diagrams of the electric drive with a harmonic signal of the speed reference with a frequency of 1 $\mathrm{Hz}$ (a) Open loop system (scalar and vector control), (b) vector control with speed feedback, (c) scalar control with DPF, (d) speed reference signal

Table 1. Experimental results with a harmonic signal of the speed reference with a frequency of $1 \mathrm{~Hz}$

\begin{tabular}{ccc}
\hline Control system type & $\Delta \omega, \mathrm{rad} / \mathrm{s}$ & $\Delta \varphi$, el. Deg \\
\hline Open loop system & $\pm 5,03$ & 84 \\
Speed feedback system & $\pm 4,99$ & 84 \\
Current feedback system & $\pm 6,4$ & 72 \\
\hline
\end{tabular}

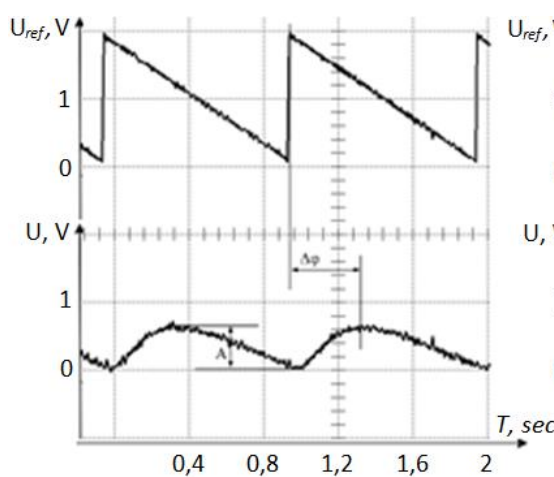

(a)

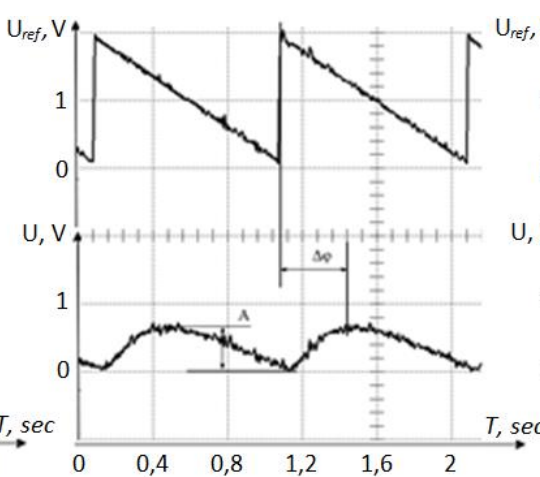

(b)

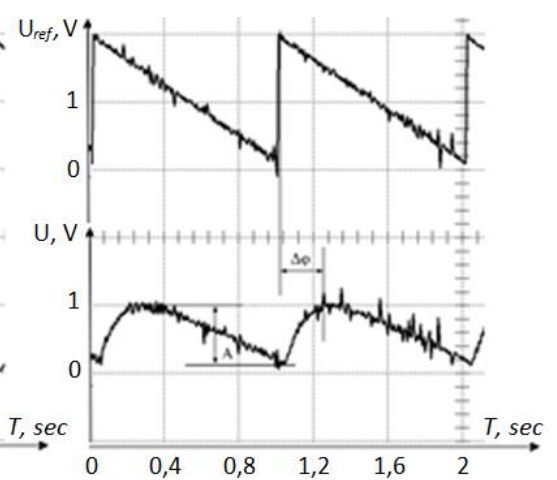

(c)

Figure 7. Diagrams of the electric drive with the open loop control system and at triangular reference signals for frequencies $1 \mathrm{~Hz}$ (a) scalar control), (b) vector control, (c) scalar control with DPF 


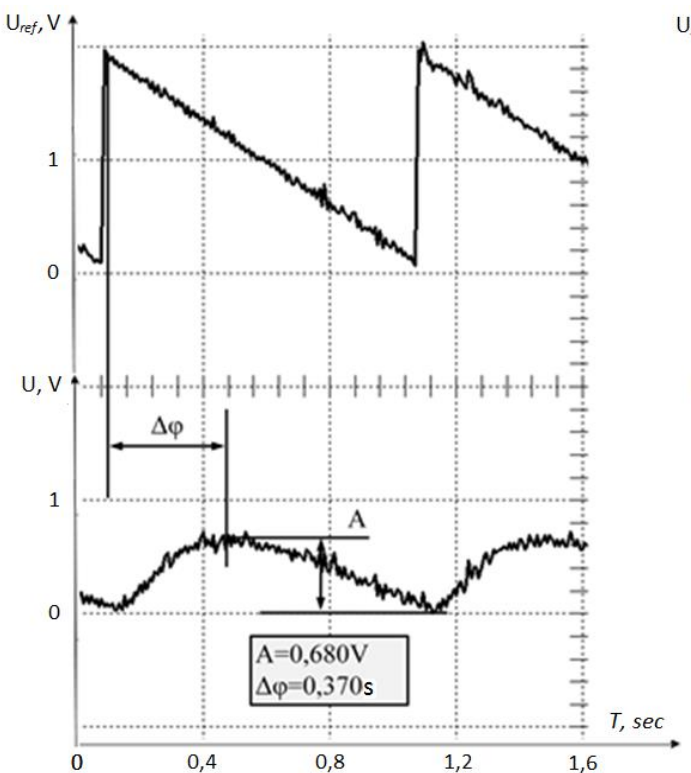

(a)

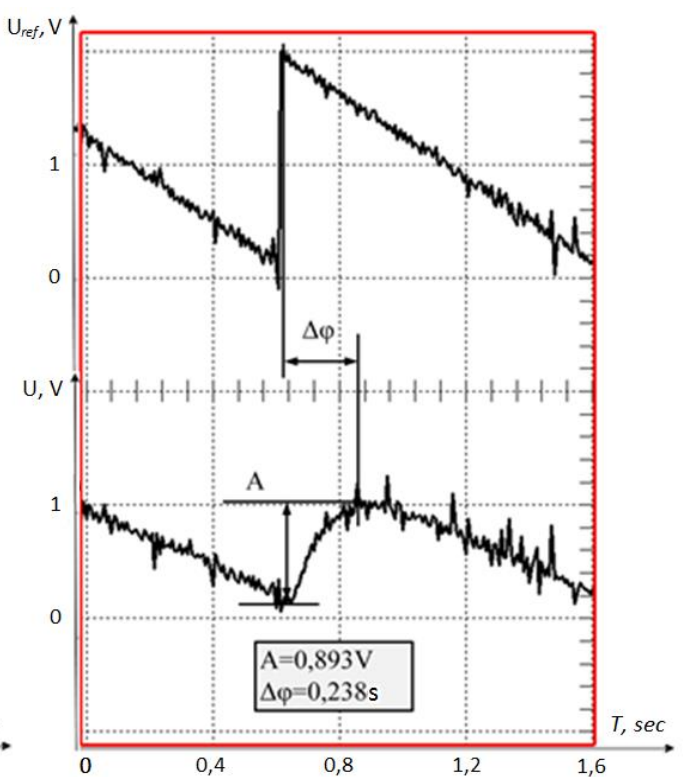

(b)

Figure 8. Enlarged diagrams of the electric drive with the open loop control system and at triangular reference signals for frequencies $1 \mathrm{~Hz}$

(a) vector control, (b) scalar control with DPF

\section{CONCLUSION}

Thus, as a result of the research carried out, the following provisions can be distinguished. The proposed experimental technique has shown its efficiency and sensitivity in assessing the dynamics of such essentially nonlinear structures as asynchronous electric drives with frequency control. It can be used in their research with the aim of optimizing for those technological complexes that require good dynamics. The technique turned out to be more laborious than traditional experimental techniques that estimate the dynamics by the response to a jump in the driving signal, but for a nonlinear system such as AEDs, this laboriousness is inevitable.

The technique is based on the previously obtained formula for the nonlinear transfer function of the link forming the electromagnetic torque, taking into account the changes in dynamics with changes in the frequency of the stator voltage and motor load. This means that this formula should also be recognized as more accurate than the vector equations of asynchronous electric motors used in the derivation of vector control (at least with changes in the frequency of the stator voltage from 10 to $50 \mathrm{~Hz}$ and in the frequency range of input signals from 0 to $5 \mathrm{~Hz}$ ).

The proposed control method with DPF for the stator current, linearizing the nonlinearities of the AED and forcing the magnetic fluxes in the motor is the most effective method for controlling the dynamic characteristics. The method of control with DPF for the stator current proposed in [20], [22] linearizes the nonlinearities of the AED and forces the magnetic fluxes in the motor. According to the results of experiments using this technique, it should be recognized as the most effective method of control according to the dynamic characteristics of the "reproduction" of signals for setting the rotation speed and recommend it for such drives (including for controlling doubly-fed electric machine of wind turbines).

\section{REFERENCES}

[1] N. A. Sukhenko, G. Ya. Pyatibratov, A. A. Danshina, L. L. Altunyan, "Prospective Electromechanical Control Systems of Industrial Manipulator Efforts," International Journal of Power Electronics and Drive System (IJPEDS), vol. 7, no. 2, pp. 416-421, 2016.

[2] Sokolovsky G.G., "electrical drives of alternating-current with frequency controlling," ACADEMIA, 2006.

[3] Alekseev V.V., Emel'yanov A.P., Kozyaruk A.E., "Analysis of the dynamic performance of a variable-frequency induction motor drive using various control structures and algorithms," Russian Electrical Engineering, vol. 87. no. 4, pp. 181-188, 2016. https://link.springer.com/article/10.3103/S1068371216040027.

[4] Figaro B.I. Pavlyachik L.B, "Regulating electrical drives of alternating-current," Technoperspectiva, pp. 363, 2006. 
[5] Goun, V.S., Anikin, A.S. \& Bakin, A.A., "Experimental determination of suboptimal parameters for energyefficient control of an induction motor," International Journal of Power Electronics and Drive Systems (IJPEDS), vol. 11, no. 4, pp. 2173-2182, 2020. doi:10.11591/ijpeds.v11.i4.pp2173-2182.

[6] Ilyina A.G., Usoltsev A.A., "Optimal motion control during positioning and its modeling in the MathLab Simulink environment," Izvestiya VUZov. Instrument making, vol. 51, no. 6, pp. 63-68, 2008.

[7] Ferreira, F.J.T.E.,De Almeida, A.T., "Overview on energy saving opportunities in electric motor driven systems Part 1: System efficiency improvement," 52nd IEEE/IAS Industrial and Commercial Power Systems Technical Conference, I and CPS, 2016. DOI: 10.1109/ICPS.2016.7490219.

[8] Usoltsev A. A., "Determination of the parameters of the asynchronous motor model according to the reference data," News of universities. Instrument making, vol. 51, no. 10, pp. 35-41, 2008.

[9] V.I. Smolin, I.G. Topol'Skaya, "Amplitude control of the moment of a three-phase asynchronous drive based on generalized energy-flow principles," Russian Electrical Engineering,.vol. 85, no. 4, pp. 205-209, 2014.

[10] Goudarzi, N., Zhu, W.D., "A review on the development of wind turbine generators across the world," Int. J. Dynam. Control, vol. 1, pp. 192-202, 2013.

[11] Li, K., Luo, H., Yang, C. and Yin, S., "Subspace-aided closed-loop system identification with application to dc motor system," IEEE Transactions on Industrial Electronics, vol. 67, no. 3, pp. 2304-2313, 2019.

[12] Ahmad, M.A., Musa, Z., Suid, M.H. and Tumari, M.Z.M., "Grey wolf optimizer for identification of liquid slosh behavior using continuous-time hammerstein model," Bulletin of Electrical Engineering and Informatics, vol. 9, no. 2, pp. 542-549, 2020. DOI: 10.11591/eei.v9i2.2074.

[13] Moradifar, A., Foroud, A.A. and Fouladi, M., "Identification of multiple harmonic sources in power system containing inverter-based distribution generations using empirical mode decomposition. IET Generation," Transmission \& Distribution, vol. 13, no. 8, pp. 1401-1413, 2019. DOI: 10.1049/iet-gtd.2018.5382.

[14] Moustafa Zair, Abdeldejbar Hazzab, "MRAS Speed Sensorless Vector Control of Induction Motor Drives Using Predictive Adaptation Mechanism," International Journal of Power Electronics and Drive Systems (IJPEDS), vol. 9, no. 4, pp. 1523-1533, 2018.

[15] Md. Rashedul Islam, Md. Maruful Islam, Md. Kamal Hossain, Pintu Kumar Sadhu, "Performance Analysis of a DTC and SVM Based Field-Orientation Control Induction Motor Drive," International Journal of Power Electronics and Drive System (IJPEDS), vol. 5, no. 3, pp. 336-343, 2015.

[16] Srinivas Gangishetti, Tarakalyani Sandipamu, "Different Control Schemes for Sensor Less Vector Control of Induction Motor," International Journal of Power Electronics and Drive System (IJPEDS), vol. 8, no. 2, pp. 712 $721,2017$.

[17] Alekseev V.V., Kozyaruk A.E., "Comparative analysis of models for systems of an automated asynchronous drive with vector control," Russian Electrical Engineering, vol. 84, no. 12, pp. 702, 2013.

[18] Marc Perron; Hoang Le-Huy, "Full Load Range Neural Network Efficiency Optimization of an Induction Motor with Vector Control using Discontinuous PWM Marc Perron; Hoang Le-Huy," IEEE International Symposium on Industrial Electronics, 2006. https://ieeexplore.iee.org/document/4077917.

[19] V.L. Kodkin, A.S. Anikin, A.A. Baldenkov, "The dynamics identification of asynchronous electric drives via frequency response," International Journal of Power Electronics and Drive Systems (IJPEDS), vol. 10, no. 1, pp. 66-73, 2019. http://ijpeds.iaescore.com/index.php/IJPEDS/article/view/15182/10882.

[20] V.L. Kodkin, A.S. Anikin, A.A. Baldenkov, "The analysis of the quality of the frequency control of induction motor carried out on the basis of the processes in the rotor circuit," XI International Scientific and Technical Conference "Dynamics of Systems, Mechanisms and Machines"-Proceedings 2017.Omsk, pp. 14-16, 2017. https://doi.org/10.1088/1742-6596/944/1/012052.

[21] V.L. Kodkin, A.S. Anikin, A.A. Baldenkov, "Spectral Analysis of Rotor Currents in Frequencycontrolled Electric Drives," 2nd International Conference on Automation, Mechanical and Electrical Engineering, AMEE 2017-Proceedings, 2017. https://doi.org/10.2991/amee-17.2017.26.

[22] V.L. Kodkin, A.S. Anikin, A.A. Baldenkov, "Performance identification of the asynchronous electric drives by the spectrum of rotor currents," International Journal of Power Electronics and Drive Systems (IJPEDS), vol. 10, no. 1, pp. 211-218, 2019.

[23] V.L. Kodkin, A.S. Anikin, A.A. Baldenkov, "Structural correction of nonlinear dynamics of frequencycontrolled induction motor drives," International Journal of Power Electronics and Drive Systems (IJPEDS), vol. 11, no. 1, pp. 220-227, 2020. http://doi.org/10.11591/ijpeds.v11.i1.pp220-227.

[24] Vladimir L. Kodkin, Alexandr S. Anikin and Alexandr A. Baldenkov, "Nonlinear Dynamics of Asynchronous Electric Drive: Engineering Interpretation and Correction Techniques," Control Theory in Engineering. IntechOpen, 2019. DOI: 10.5772/intechopen.88223.

[25] V.L. Kodkin, A.S. Anikin, A.A. Baldenkov, "Stabilization of the stator and rotor flux linkage of the induction motor in the asynchronous electric drives with frequency regulation," International Journal of Power Electronics and Drive Systems (IJPEDS), vol. 11, no. 1, pp. 213-219, 2020. http://doi.org/10.11591/ijpeds.v11.i1.pp213-219. 